\title{
Influence of women's autonomy on infant mortality in Nepal
}

Ramesh Adhikari ${ }^{1,2^{*}}$ and Yothin Sawangdee ${ }^{2}$

\begin{abstract}
Background: Nepalese women lag behind men in many areas, such as educational attainment, participation in decision-making and health service utilization, all of which have an impact on reproductive health outcomes. This paper aims to examine the factors influencing infant mortality, specifically, whether women's autonomy has an impact on infant mortality in the Nepali context.

Methods: Data were drawn from the Nepal Demographic and Health Survey, 2006. The analysis is confined to 5,545 children who were born within the five years preceding the survey. Association between infant mortality and the explanatory variables was assessed using bivariate analysis. Variables were then re-examined in multivariate analysis to assess the net effect of women's autonomy on infant mortality after controlling for other variables.

Results: The infant mortality rate (IMR) in the five years preceding the survey was 48 deaths per one thousand live births. Infant mortality rate was high among illiterate women (56 per 1000 live births) and among those not involved in decision making for health care (54 per 1000 live births). Furthermore, infant mortality was high among those women who had more children than their comparison group, who had birth intervals of less than two years, who had multiple births, who were from rural areas, who were poor, whose source of water was the river or unprotected sources, and who did not have a toilet facility in their household.

Results from logistic regression show that women's autonomy plays a major role in infant mortality after controlling other variables, such as mother's sociodemographic characteristics, children's characteristics and other household characteristics. Children from literate women had a 32 percent lower chance $(O R=0.68)$ of experiencing infant mortality than did children from illiterate women. Furthermore, infants of women who were involved in decision-making regarding their own health care had a 25 percent lower $(O R=0.75$ ) chance of dying than did infants whose mothers who were not involved in healthcare decisions.

Conclusion: Infant mortality is high in Nepal. In this context, mother's literacy and involvement in healthcare decision making appear to be the most powerful predictors for reducing infant mortality. Hence, in order to reduce infant mortality further, ongoing female education should be sustained and expanded to include all women so that the millennium development goals for the year 2015 can be attained. In addition, programs should focus on increasing women's autonomy so that infant mortality will decrease and the overall well being of the family can be maintained and enhanced.
\end{abstract}

\section{Background}

As in other many developing countries, high infant mortality has been a major public health problem in Nepal. Although over the past few decades, Nepal has seen substantial improvements in its reproductive health outcomes, infant and child mortality as well as maternal

\footnotetext{
* Correspondence: rameshipsr@gmail.com

'Geography and Population Department, Mahendra Ratna Campus,

Tribhuvan University, Kathmandu, Nepal

Full list of author information is available at the end of the article
}

mortality remain high compared to rates in other developing countries.

In many societies women's inferior social status and status within the household adversely affect their health and that of their children. The health of women and their children is largely impaired by culturally and socially determined roles for women through a complex web of physiological and behavioral interrelationships and synergies that permeate every aspect of their lives [1]. Much research has shown that higher status for

\section{Biomed Central}


women correlates positively with their and their children's health $[2,3]$.

It is well documented that women almost everywhere are disadvantaged compared to men in terms of their access to assets, employment, health care, and education. Since the social status and level of autonomy of Nepali women is low, their status at the household level needs to be further explored in terms of health services utilization, which has a direct impact on maternal and infant morbidity and mortality. This relationship clearly warrants further attention, particularly in settings such as Nepal, where maternal and child health utilization is low [4].

A substantial body of research has examined the role of women's autonomy on health and behavioral outcomes such as fertility [5,6], family planning [7-9], and child rearing and pregnancy care [10-13]. However, only a few studies have assessed the role of women's autonomy on child survival or infant mortality $[14,15]$.

This study is an attempt to examine the prevalence and factors influencing infant mortality. More specifically, it aims to investigate whether women's autonomy has an impact on infant mortality in Nepal. In addition, this paper also aims to close the knowledge gap in the literature with regard to a society in which women suffer gross disadvantages in the context of a patriarchal culture, which in turn can help guide reproductive health program planners and policy makers to understand various factors influencing infant mortality and to assist in implementation of reproductive health programs that will decrease infant morbidity and mortality. Though there are a few studies that have assessed the relationship between women's autonomy and infant mortality outside the country, to our knowledge this type of research has not yet been undertaken in Nepal.

\section{Data and Methods}

This paper reports on data drawn from the Nepal Demographic and Health Survey (NDHS), 2006, a nationally representative sample survey. The primary purpose of the 2006 NDHS was to furnish policymakers and planners with detailed information on fertility, family planning, infant/child/adult/maternal mortality, maternal and child health, nutrition, and knowledge of HIV/AIDS and other sexually transmitted infections. The 2006 NDHS was carried out under the aegis of the Population Division of the Ministry of Health and Population. The data from this survey is openly available.

The 2006 NDHS used the sampling frame provided by the list of census enumeration areas with population and household information from the 2001 Population Census. Each of the 75 districts in Nepal is subdivided into Village Development Committees (VDCs), and each VDC into wards. The primary sampling unit (PSU) for the 2006 NDHS is a ward, sub-ward, or group of wards in rural areas, and sub-wards in urban areas. The sample for the survey is based on a two-stage, stratified, nationally representative sample of households. At the first stage of sampling, 260 PSUs (82 in urban areas and 178 in rural areas) were selected using systematic sampling with probability proportional to size. At the second stage of sampling, systematic samples of about 30 households per PSU on average in urban areas and about 36 households per PSU on average in rural areas were selected in all the regions. Interviews were completed for 10,793 women of reproductive age.

Infant mortality rate (IMR) is defined as the number of deaths of infants under age 1 per 1,000 live births in a given year. In the present study, women's autonomy refers to the education status of women, and women's household decision-making autonomy, which was measured based on responses to "Who makes the following decisions in (respondent's) household about: 1) obtaining health care for yourself; 2) large household purchases; 3) household purchases for daily needs; and 4) visits to family or relatives?" Response options were: a) respondent alone; b) respondent and husband/partner; c) respondent and other person; d) husband/partner alone; e) someone else; f) other. The value of 1 is assigned if the response was (a), (b), or (c), that is, involvement of the respondent, or else 0 , for no involvement of the respondent. The other independent variables included in this study were demographic and socioeconomic variables such as age, religion, number of children born, previous birth interval, sex of the child, type of birth, place of residence, ecological zone, wealth status of households, sources of drinking water, and availability of toilet facilities.

The unit of analysis in our study is children who were born within the five-year period $(\mathrm{n}=5545)$ preceding the survey interview. Data were weighted to represent the structure of Nepali population using weighting factors provided with the NDHS. Association between infant mortality and the explanatory variables was assessed in bivariate analysis using Chi-square tests. Logistic regression was used to assess the net effect of mother's autonomy on infant mortality after controlling several other control variables. Two models were used in the analysis. The first model contained the variables related to women's autonomy. In the second model, other demographic and socioeconomic characteristics were added. Prior to the multivariate analysis, multi-collinearity between the variables was assessed. However, no multi-collinearity was found among the variables. Only those variables that were significant in the bivariate analysis were further analyzed in logistic regression. The Statistical Package for Social Science (SPSS 17.0 for Windows) software was used to analyze the data. 


\section{Results}

Three out of five mothers (60\%) were illiterate. Only about half or less (43\%-51\%) of mothers were involved in decisions regarding their own health care, large household purchases, household purchases for daily needs, and visits to family or relatives. More than twofifths of mothers (42\%) were below 25 years of age. A considerable proportion of the infants (32\%) had four or more siblings. A majority of the mothers had birth spacing of two-three years. More than a quarter of households drank water from unprotected sources (e.g., a river or unprotected well). Notably, more than threefifths $(63 \%)$ of houses did not have toilet facilities at the time of the survey (Table 1).

The infant mortality rate in the five years preceding the survey was 48 deaths per one thousand live births. The IMR varied significantly with different settings. For instance, the IMR was higher among illiterate women
(56 per 1000 live births) than among literate women (35 per 1000 live births). Similarly, the IMR was significantly higher among women who were not involved in decision making for their own health care (54 per 1000 live births) than among those who were involved in the decision-making process for their own health care (40 per 1000 live births). Furthermore, the IMR was lower among women aged 25-29 (39 per 1000 live births) than among other age groups (56 per 1000 live births among women aged 15-24 and 46 per 1000 live births among women aged 30 or above). Moreover, the IMR was significantly higher among Muslim women, who had more children (36 per 1000 live births among women who had one child and 59 per 1000 live births among those who had four or more children). Similarly IMR was significantly higher among those who had less than twoyear birth intervals (62 per 1000 live births), among those who had multiple births (382 per 1000 live births),

Table 1 Selected background characteristics

\begin{tabular}{|c|c|c|c|}
\hline Characteristics & & $\%$ & $\mathbf{N}$ \\
\hline \multicolumn{4}{|l|}{ Women's autonomy } \\
\hline \multirow[t]{2}{*}{ Literacy status } & Illiterate & 60.3 & 3,343 \\
\hline & Literate & 39.7 & 2,202 \\
\hline \multirow[t]{2}{*}{ Decision on own health care } & Without involvement of respondent & 56.7 & 3,146 \\
\hline & Involvement of respondent & 43.3 & 2,398 \\
\hline \multirow[t]{2}{*}{ Decision on making large household purchases } & Without involvement of respondent & 55.0 & 3,047 \\
\hline & Involvement of respondent & 45.0 & 2,497 \\
\hline \multirow[t]{2}{*}{ Decision on making household purchases for daily needs } & Without involvement of respondent & 49.3 & 2,734 \\
\hline & Involvement of respondent & 50.7 & 2,811 \\
\hline \multirow[t]{2}{*}{ Decision on visits to family or relatives } & Without involvement of respondent & 50.6 & 2,808 \\
\hline & Involvement of respondent & 49.4 & 2,736 \\
\hline \multicolumn{4}{|l|}{ Demographic and socioeconomic characteristics } \\
\hline \multirow[t]{3}{*}{ Age group } & $<25$ & 41.5 & 2,299 \\
\hline & $25-29$ & 31.4 & 1,742 \\
\hline & 30 or older & 27.1 & 1,504 \\
\hline \multirow[t]{3}{*}{ Religion } & Buddhist & 7.4 & 411 \\
\hline & Hindu & 84.9 & 4,706 \\
\hline & Muslim/other & 7.7 & 428 \\
\hline \multirow[t]{4}{*}{ Total children ever born } & One & 19.7 & 1,094 \\
\hline & Two & 29.7 & 1,649 \\
\hline & Three & 18.5 & 1,025 \\
\hline & Four or more & 32.1 & 1,777 \\
\hline \multirow[t]{3}{*}{ Previous birth interval } & $<2$ years & 21.9 & 847 \\
\hline & $2-3$ years & 55.6 & 2,148 \\
\hline & $4+$ years & 22.4 & 866 \\
\hline \multirow[t]{2}{*}{ Source of drinking water } & Piped/tube well water & 72.4 & 4,014 \\
\hline & River/stone tap/unprotected well & 27.6 & 1,531 \\
\hline \multirow[t]{2}{*}{ Toilet facility } & Yes & 37.2 & 2,061 \\
\hline & No facility/bush/field & 62.8 & 3,484 \\
\hline Total & & 100.0 & 5,545 \\
\hline
\end{tabular}


Table 2 Infant mortality rates (per 1,000 live births) for 5-year periods preceding the survey, by background characteristics $(N=5,545)$

\begin{tabular}{|c|c|c|}
\hline \multicolumn{2}{|l|}{ Characteristics } & \multirow[t]{2}{*}{ IMR } \\
\hline Women's Autonomy & & \\
\hline \multirow{2}{*}{ Literacy status $* * *$} & Illiterate & 56 \\
\hline & Literate & 35 \\
\hline \multirow[t]{2}{*}{ Decision on own health care * } & Without involvement of respondent & 54 \\
\hline & Involvement of respondent & 40 \\
\hline \multirow[t]{2}{*}{ Decision on making large household purchases } & Without involvement of respondent & 50 \\
\hline & Involvement of respondent & 45 \\
\hline \multirow[t]{2}{*}{ Decision on making household purchases for daily needs } & Without involvement of respondent & 53 \\
\hline & Involvement of respondent & 45 \\
\hline \multirow[t]{2}{*}{ Decision on visits to family or relatives } & Without involvement of respondent & 53 \\
\hline & Involvement of respondent & 42 \\
\hline \multicolumn{3}{|l|}{ Sociodemographic variables } \\
\hline \multirow[t]{3}{*}{ Age group * } & $<25$ years & 56 \\
\hline & $25-29$ & 39 \\
\hline & 30 or more & 46 \\
\hline \multirow[t]{3}{*}{ Religion * } & Buddhist & 26 \\
\hline & Hindu & 48 \\
\hline & Muslim/other & 65 \\
\hline \multirow[t]{4}{*}{ Total children ever born * } & One & 36 \\
\hline & Two & 43 \\
\hline & Three & 48 \\
\hline & Four or more & 59 \\
\hline \multirow[t]{3}{*}{ Previous birth interval ** } & $<2$ years & 62 \\
\hline & $2-3$ years & 41 \\
\hline & $4+$ years & 27 \\
\hline \multirow[t]{2}{*}{ Sex of child } & Female & 53 \\
\hline & Male & 42 \\
\hline \multirow[t]{2}{*}{ Type of births $* * *$} & Singleton & 42 \\
\hline & Multiple & 382 \\
\hline \multirow[t]{2}{*}{ Place of residence } & Urban & 34 \\
\hline & Rural & 50 \\
\hline \multirow[t]{3}{*}{ Ecological zone *** } & Terai & 53 \\
\hline & Hill & 36 \\
\hline & Mountain & 75 \\
\hline \multirow[t]{2}{*}{ Wealth status ** } & Poor/middle & 54 \\
\hline & Rich & 35 \\
\hline \multirow[t]{2}{*}{ Source of drinking water * } & Piped/tube well water & 44 \\
\hline & River/stone tap/unprotected well & 57 \\
\hline \multirow[t]{2}{*}{ Availability of Toilet facility* } & Yes & 39 \\
\hline & No facility/bush/field & 53 \\
\hline Total & & 48 \\
\hline
\end{tabular}

among those who lived in the Mountain region (75 per 1000 live births), among those who were poor (54 per 1000 live births), among those whose sources of drinking water was a river or other unprotected sources (57 per 1000 live births), and among those who did not have toilet facilities in their house (53 per 1000 live births) than their comparison group (Table 2).

In the first model of logistic regression, both women's autonomy-related variables had a statistically significant effect on infant mortality. Literate women had 39 percent 
lower odds $(\mathrm{OR}=0.61)$ of experiencing infant mortality than did illiterate women. Similarly, women who were involved in the decision-making process for their own health care had a 26 percent lower chance $(\mathrm{OR}=0.74)$ of experiencing infant mortality than those who were not involved in the decision-making process regarding their own health care.

Model 2 presents the final results after adding other demographic and socioeconomic characteristics of the women, as well as household characteristics. Even after inclusion of these variables in model 2, women's autonomy variables retained their significance level. Furthermore, the reduction of the significance level of women's autonomy variables after inclusion of the other variables indicates that demographic and socioeconomic variables are also important predictors for infant mortality. Moreover, women's age, number of children ever born, religion, previous birth interval, and type of births were also significant predictors of infant mortality. Age has a negative and statistically significant impact on infant mortality; as the age of women increased, infant mortality decreased. On the other hand, the larger the number of a woman's total number of children ever born the larger the IMR. Infants born of Hindu and Muslim women were more likely to die than those born of Buddhist women. Furthermore, infants from mothers who had two-or-three-year and four-year or more birth intervals had 55 percent and 68 percent, respectively, lower odds of dying than did infants whose mothers had previous birth intervals of less than two years. Notably, infants born as twins were more likely $(\mathrm{OR}=14.5)$ to die before reaching one year than were single-birth infants (Table 3).

\section{Discussion}

This study aimed to examine the factors influencing infant mortality in Nepal, specifically, by investigating whether the women's autonomy has an impact on infant mortality. Results show that infant mortality is high in Nepal, thus indicating an unmet need to be addressed by maternal and child health programs.

Bivariate analysis shows that variables such as women's autonomy (namely, literacy status of women and decision making regarding their own health care), religion, number of children ever born, previous birth interval, type of birth (single or multiple), ecological zone, wealth status, sources of drinking water, and availability of toilet facilities in a household are important variables in explaining infant mortality. The multivariate analysis supported most of the findings of the bivariate analysis. In the multivariate analysis women's autonomy (literacy status and decision making regarding their own health care), age group, total number of children born, previous birth interval, and type of birth were significant predictors of infant mortality.
As do many other studies, this study also shows that literate mothers have a lower experience of infant deaths. It could be that educated mothers are more capable of accessing available health facilities and that they are able to greatly change the traditional balances of power and autonomy in familial relationships, with profound effects on child care [16]. Moreover, education can contribute to children's survival by making women more likely to marry and give birth later and to have fewer children, utilize prenatal care, and immunize their children [17]. Anther reason could be that schools are institutions that transform young girls into empowered, assertive, and confident women [18].

Our study showed that infant mortality is significantly lower among those mothers who were involved in decisions regarding their own health care compared to those who were not. A possible explanation could be that women who have autonomy in decision making are more likely to have a higher level of contraceptive use, which might lessen their reproductive behavior risks, prolong birth intervals, lower fertility [5], and result in lower infant mortality. A study in India has confirmed that a women's control over household resources (ability to keep money aside) has a significant positive effect on both the demand for prenatal care and the probability of hospital delivery [19].

Our study showed that infants from older women were less likey to die before reaching their first birthday. It could be that the bodies of young mothers are not selective enough with respect to malformed fetuses, which results in higher rates of stillbirths and hypothrophic births, and thus in higher infant mortality [20-22]. As do many other studies, this study shows a strong relationship between fertility behavior of women and child death. Infants born of those women who had given birth to more children were more likely to die than were infant froms those mothers who had given birth to only one child. It could be that as a family grows the parental resources might be insufficient to maintain the same level of nutrition for a larger number of children, and thus those born earlier might enjoy better nutritional status than those born later [23]. Short birth spacing and high birth order may affect both maternal and fetal health as well as availability of time for child care. This finding conforms with other studies that find that the length of the birth interval is positively correlated with the survival of the infant child [24-27]. Our study found that the probability of infant mortality is very high in the case of multiple births. This effect is mainly associated with the lower birth weight of twins or triplets, which in trun is one of the most important factors affecting neo-natal survival. The reason could be that the arrival of more than one child also creates extra demand for food. During the early stages of infancy, 
Table 3 Adjusted odds ratios (OR) and $95 \%$ confidence interval (CI) for infant mortality within the past five years preceding the survey by selected predictors

\begin{tabular}{|c|c|c|c|c|c|}
\hline \multirow[t]{2}{*}{ Selected predicators } & & \multicolumn{2}{|c|}{ Model I } & \multicolumn{2}{|c|}{ Model II } \\
\hline & & OR & $\mathrm{Cl}$ & OR & $\mathrm{Cl}$ \\
\hline \multicolumn{6}{|l|}{ Women's Autonomy } \\
\hline \multirow[t]{2}{*}{ Literacy status } & Illiterate (ref.) & 1.00 & & 1.00 & \\
\hline & Literate & $0.61^{* * *}$ & $0.47-0.80$ & $0.65^{*}$ & $0.47-0.90$ \\
\hline \multirow[t]{2}{*}{ Decision on own health care } & Without involvement of respondent (ref.) & 1.00 & & 1.00 & \\
\hline & Involvement of respondent & $0.74^{*}$ & $0.57-0.95$ & $0.75^{*}$ & $0.57-0.98$ \\
\hline \multicolumn{6}{|l|}{ Sociodemographic variables } \\
\hline \multirow[t]{3}{*}{ Age } & $<25$ years (ref.) & & & 1.00 & \\
\hline & $25-29$ & & & $0.57^{* *}$ & $0.39-0.83$ \\
\hline & 30 or more & & & $0.57^{* *}$ & $0.36-0.91$ \\
\hline \multirow[t]{4}{*}{ Total number of children ever born } & One (ref.) & & & 1.00 & \\
\hline & Two & & & $1.62^{*}$ & $1.07-2.45$ \\
\hline & Three & & & $2.58^{* * *}$ & $1.59-4.19$ \\
\hline & Four or more & & & $3.21^{* * *}$ & $1.89-5.45$ \\
\hline \multirow[t]{3}{*}{ Religion } & Buddhist (ref.) & & & 1.00 & \\
\hline & Hindu & & & $1.96^{*}$ & $1.02-3.79$ \\
\hline & Muslim/other & & & $2.32^{*}$ & $1.08-5.02$ \\
\hline \multirow[t]{3}{*}{ Previous birth interval } & $<2$ years (ref.) & & & 1.00 & \\
\hline & $2-3$ years & & & $0.45^{* * *}$ & $0.33-0.61$ \\
\hline & $4+$ years & & & $0.30^{* * *}$ & $0.18-0.50$ \\
\hline \multirow[t]{2}{*}{ Type of births } & Singleton (ref.) & & & 1.00 & \\
\hline & Multiple & & & $14.5^{* * *}$ & 8.89-23.6 \\
\hline \multirow[t]{3}{*}{ Ecological zone } & Terai (ref.) & & & 1.00 & \\
\hline & Hill & & & 0.81 & $0.58-1.12$ \\
\hline & Mountain & & & 1.47 & $0.97-2.25$ \\
\hline \multirow[t]{2}{*}{ Wealth status } & Poor/middle (ref.) & & & 1.00 & \\
\hline & Rich & & & 0.83 & $0.59-1.17$ \\
\hline \multirow[t]{2}{*}{ Source of drinking water } & Piped/tube well water (ref.) & & & 1.00 & \\
\hline & River/stone tap/unprotected well & & & 1.24 & $0.91-1.68$ \\
\hline \multirow[t]{2}{*}{ Availability of Toilet facility } & Yes (ref.) & & & 1.00 & \\
\hline & No facility/bush/field & & & 0.82 & $0.59-1.14$ \\
\hline Constant & & $0.07^{* * *}$ & & $0.04^{* * *}$ & \\
\hline-2 Log likelihood & & 2105.6 & & 1918.5 & \\
\hline Cox \& Snell R Square & & 0.003 & & 0.037 & \\
\hline
\end{tabular}

Note ${ }^{* *}$ Significant at $p<0.001 ;{ }^{* *}=p<0.01$ and ${ }^{*}=p<0.05$

since breast feeding is one of the main sources of nutrition, multiple births might lead to infants' lower calorie intake, and thus to lower survival chances [28].

This study found that infants born of Hindu and Muslim women were more likley to die than were infants from Buddhist women. It could be that Hindu and Muslim girls tend to marry at an earlier age, which leads to conception at an earlier age, which in turn increases the risk of child morbidity and mortality. The other reason could be that cultural beliefs and practices often lead to self-care, home remedies, and consulation with traditional healers [29]. These factors might result in delays in treatment seeking, which are more common among women, not only with regard to their own health but, especially, with regard to children's illnesses [30-32].

There are some limitations in the interpretation of the results of this study. Women's autonomy is a complex phenomenon that cannot be completely measured by education and only a few household decision-making indicators. Similarly, as pointed out previously, we restricted our subjects to mothers whose infants who were born within the five years preceding the survey, so our results regarding the prevalence of infant mortality should be generalized with care. Comparisons between surveys should also be interpreted with caution because quality of data and sample coverage varies. Because the 
cross-sectional design of the study and all of the items analyzed in the logistic regression analysis came from information at the time of survey, the analysis can only provide evidence of statistical association between those items and infant mortality and cannot show cause-effect relationships. Furthermore, we should not forget other important errors that could exist in the collection of information regarding infant deaths. Women tend to omit noting children who may have died in very early days after their birth. However, since the 1991 fertility and family planning survey in Nepal, it has been argued that the quality of pregnancy history data has improved and that there is very little omission of births and deaths, especially during the recent past. As the effect of these omissions on the calculation of demographic rates is minimal, a direct method of estimation has been used since then [33]. There may in fact be very few errors in this regard as it is believed that the Nepal Demographic and Health Survey data were good enough to estimate mortality directly [4].

\section{Conclusions}

In Nepal, women's autonomy is a strong predictor among many other predictors of infant mortality. Mothers' literacy and decision-making power regarding health care appear to be the most powerful predictors among many others for reducing infant mortality. Hence, in order to reduce infant mortality further, ongoing female education should be sustained and broadened to include every woman in order to reach the MDG goal for the year 2015. If programs focus on increasing women's autonomy, infant mortality will decrease and the overall well being of the family will be maintained and be enhanced.

\section{Acknowledgements}

The authors thanks MEASURE DHS + for providing access to the data.

\section{Author details}

${ }^{1}$ Geography and Population Department, Mahendra Ratna Campus, Tribhuvan University, Kathmandu, Nepal. ${ }^{2}$ Institute for Population and Social Research, Mahidol University, Salaya, Phutthamonthon, Nakhon Pathom 73170, Thailand.

\section{Authors' contributions}

RA analyzed and interpreted the data and drafted the manuscript. YS commented on the analysis and provided suggestions. Both authors read and approved the final version of the manuscript.

\section{Competing interests}

The authors declare that they have no competing interests.

Received: 22 February 2011 Accepted: 19 April 2011

Published: 19 April 2011

\section{References}

1. Santow G: Gender differences in health and risks and use of services. Population and women. Proceedings of the United Nations expert group meeting on population and women Gaborone, Botawana, 22-26 June 1992 New York: United Nation; 1995.

2. Castle SE: Intra-household differentials in women's status: household function and focus as determinants of children's illness management and care in Rural Mali. Health Transition Review 1993, 3(2):137-157.

3. Gupta DM: Death clustering mothers' education and the determinants of child mortality in Rural Pujab, India. Population studies 1990, 44(3):489-505.

4. Ministry of Health [Nepal], New Era, and ORC Macro: Nepal Demographic and Health Survey 2001. Calverton, Maryland, USA: Family Health Division, Ministry of Health; New Era and ORC Macro; 2002.

5. Dyson T, Moore M: On kinship structure, female autonomy, and demographic behavior in India. Population and Development Review 1983, 9(1):35-60.

6. Abadian S: Women's autonomy and its impact on fertility. World Development 1996, 24(12):1793-1809.

7. Al Riyami A, Afifi M, Mabry RM: Women's autonomy, education and employment in Oman and their influence on contraceptive use. Reproductive Health Matters 2004, 12(23):144-154.

8. Hogan DP, Berhanu B, Hailemariam A: Household organization, women's autonomy and contraceptive behavior in Southern Ethiopia. Studies in Family planning 1999, 30(4):302-314

9. Saleem S, Bobak M: Women's autonomy, education and contraception use in Pakistan: a national study. Reproductive Health 2005, 2(1):8.

10. Matsumura M, Gubhaju B: Women's status, household structure and utilization of maternal health services in Nepal. Asia Pacific Population Journal 2001, 16(1):23-43.

11. Mullany BC, Hindin MJ, Becker S: Can women's autonomy impede male involvement in pregnancy health in Kathmandu Nepal. Social Science and Medicine 2005, 61(9):1993-2006.

12. Mistry R, GalalO Lu M: Women's autonomy and pregnancy care in rural India: A contextual analysis. Social Science and Medicine 2009, 69:926-933.

13. Woldemicael G, Tenkorang FY: Women's autonomy and maternal health seeking behavior in Ethiopia. Maternal and Child Health Journal 2010, 14:988-998.

14. Ghuman SJ: Women's autonomy and child survival: a comparison of Muslims and non-Muslims in four Asian countries. Demography 2003, 40(3):419-36.

15. Shroff M, Griffiths P, Adair L, Suchindran C, Bentley M: Maternal autonomy is inversely related to child stunting in Andhra Pradesh, India. Maternal and Child Nutrition 2009, 5(1):64-74.

16. Caldwell JC: Maternal education as a factor in child mortality. World Health Forum 1981, 2:75-77.

17. Hobcraft J: Women's education, child welfare and child survival: a review of the evidence. Health Transition Review 1993, 3(2):159-173.

18. Jejeebhoy S: Women's education, autonomy and reproductive behavior: Experience from developing countries. Oxford: Clarendon Press; 1995.

19. Maitra P: Parental bargaining, health inputs and child mortality in India. Journal of Health Economics 2004, 23:259-291.

20. Gray R, Leridon H, Spira A: Biomedical and demographic determinants of reproduction. Oxford: Clarendon Press; 1993.

21. Weinstein M, Wood JW, Change MC: Age patterns of fecundability. In Biomedical and demographic determinants of reproduction. Edited by: Gray R, Leridon H, Spira A. Oxford: Clarendon Press; 1993:209-227.

22. Wood JW: Dynamics of human reproduction: Biology, Biometry, Demography. New York: Aldine de Gruyter; 1994.

23. Blake J: Family size and the quality of children. Demography 1981, 18(4):421-442.

24. Antonovosky A, Bernstein J: Social class and infant mortality. Social Science and Medicine 1977, 11:453-470.

25. Boerma JT, Bicego GT: Preceding birth interval and child survival: searching for pathway of influence. Studies in Family Planning 1992, 23(4):243-256.

26. Knodel J, Hermalin Al: Effect of birth rank, maternal age, birth interval and sibship size on infant and child mortality: Evidence from $18^{\text {th }}$ and $19^{\text {th }}$ century reproductive histories. American Journal of Public Health 1984 74:1098-1106.

27. Palloni A, Millman S: Effects of inter birth intervals and breastfeeding on infant and early childhood mortality. Population Studies 1986, 40(2):215-236.

28. Tymicki K: Correlates of infant and childhood mortality: A theoretical overview and new evidence from the analysis of longitudinal data of 
the Bejsce (Poland) parish register reconstitution study of the $18^{\text {th }}-20^{\text {th }}$ centuries. Demographic Research 2009, 20(23):559-594.

29. Nyamongo IK: Health care switching behavior of malaria patients in a Kenyan rural community. Social Science and Medicine 2002, 54:377-386.

30. Nakagawa YM, Ozasa K, Yamada N, Osuga K, Shimouchi A, Ishikawa N, Bam DS, Mori T: Gender difference in delays to diagnosis and health care seeking behavior in a rural area of Nepal. The international Journal of Tuberculosis and Long diseases 2001, 5:24-31.

31. McNee A, Khan N, Dawson S, Gunsalam J, Tallo VL, Manderson L, Riley I: Responding to cough: Boholano illness classification and resort to care in response to childhood ARI. Social Science and Medicine 1995,

40:1279-1289.

32. Kaona FAD, Siziya S, Mushanga M: The problems of a social survey in epidemiology: an experience from a Zambian rural community. African Journal of Medicine and Medical Sciences 1990, 19:219-224.

33. CBS: Population monograph of Nepal. Central bureau of statistics, Kathmandu; 2003.

doi:10.1186/1742-4755-8-7

Cite this article as: Adhikari and Sawangdee: Influence of women's autonomy on infant mortality in Nepal. Reproductive Health 2011 8:7.

\section{Submit your next manuscript to BioMed Central} and take full advantage of:

- Convenient online submission

- Thorough peer review

- No space constraints or color figure charges

- Immediate publication on acceptance

- Inclusion in PubMed, CAS, Scopus and Google Scholar

- Research which is freely available for redistribution

Submit your manuscript at www.biomedcentral.com/submit 